Revistade
Economild
Contemporâned

Articles

\title{
ASSESSING COMPETITION IN BRAZIL'S ELECTRICITY MARKET IF BID-BASED DISPATCH WERE ADOPTED
}

\author{
Richard L. Hochstetler \\ João D. Cho ${ }^{b}$ \\ ${ }^{\mathrm{a}}$ Director of Economic and Regulatory Studies at Instituto Acende Brasil. São Paulo, SP, \\ Brazil. ORCID: https://orcid.org/0000-0002-7012-504X. \\ 'Engineer at Instituto Acende Brasil. São Paulo, SP, Brazil. ORCID: \\ https://orcid.org/0000-0003-1165-8687.
}

Manuscript received on 2018/04/18 and accepted for publication on 2018/09/27.

\begin{abstract}
Market simulation, based on structural characteristics, is a useful tool for ex-ante competition analysis of major market changes, such as: market liberalization, mergers and acquisitions, divestitures, and regulatory reforms. In this paper, Cournot-Nash simulation is used to evaluate the expected market equilibrium if the Brazilian electricity market were liberalized. A sensitivity analysis is utilized to evaluate how the market equilibrium is impacted by different factors, such as: different demand price elasticities, divestiture of the dominant market player, different initial equilibrium point and different hydro inflow scenarios.
\end{abstract}

KEYWORDS: antitrust; electricity market; Cournot-Nash simulation.

JELCODES: D43; L13; L40; L94.

Corresponding author: Richard L. Hochstetler

E-mail address: richard@acendebrasil.com.br 


\section{AVALIAÇÃO CONCORRENCIAL DO MERCADO DE ENERGIA BRASILEIRO COM DESPACHO POR OFERTA}

RESUMO: Simuladores de mercado, considerando características estruturais, são ferramentas úteis para a realização de análise concorrencial ex-ante de mudanças fundamentais no mercado, tais como: liberalização de mercado, fusões e aquisições, desinvestimentos e reformas regulatórias. Nesse artigo, simulações Cournot-Nash são utilizadas para avaliar o equilíbrio de mercado esperado se o mercado de energia elétrica no Brasil fosse liberalizado. Uma análise de sensibilidade é utilizada para avaliar como o equilíbrio de mercado é impactado por diferentes fatores, tais como: diferentes elasticidades-preço da demanda, desinvestimentos realizados pela empresa dominante, diferentes pontos de equilíbrio iniciais e diferentes cenários hidrológicos.

PALAVRAS-CHAVE: defesa da concorrência; mercado de energia elétrica; simulação Cournot-Nash. 


\section{INTRODUCTION ${ }^{1}$}

Competition analysis is typically based on own and cross-price elasticities estimates determined from historical market data. However, how can one evaluate the likely behavior of agents in a market that does not yet exist? The question may sound strange, but it is often the situation policymakers face when restructuring regulated markets.

The electric power sector is a field in which this situation has often occurred. In the past few decades policymakers in many jurisdictions have undertaken regulatory reforms to unbundle electricity provision to enable market provision of power generation, while maintaining regulated prices for the remaining services (transmission, distribution and ancillary services).

Prior to electricity market reforms, the consumer's price and income elasticities for bundled services may be inferred from historical price and quantity data, but there is no track record from which to analyze the power suppliers' behavior if prices are unregulated, nor to estimate the price elasticities for the various unbundled services. On the other hand, given that these activities were previously subject to price regulation, policymakers can usually count on relatively detailed information on the suppliers' capacities, production cost structures, and system logistical constraints (such as transmission bottlenecks) - valuable structural information from which market simulators can be built.

In this context, market simulation can provide policymakers valuable guidance as to the likely market equilibrium for unbundled products.

The Brazilian electricity power system is currently operated in a command-andcontrol manner by the System Operator, which determines when and how much each power plant produces, based on official computer models. These models also determine spot market prices considering thermal power plant's marginal costs of operation and the opportunity cost of potential energy stored in hydro reservoirs. In this context, market transactions are limited to long-term contracts that are offered by power producers based on expectations on how the system will be operated and on corresponding expected market prices. Given the power producers' lack of operational autonomy, however, the current market arrangement is contentious and subject to much litigation.

In this paper, Cournot-Nash simulation is used to assess what the likely market equilibrium would be if the Brazilian electricity spot market were liberalized, so as to enable power producers to compete directly in the spot market by means of bids

\footnotetext{
1 Este estudo foi realizado no âmbito do Programa de P\&D da Aneel, PD-0678-0314-2014, patrocinado pela EDF Norte Fluminense, EDP e Energisa, executado pelo Instituto Acende Brasil.
} 
specifying the price at which they are willing to supply electricity. The simulation seeks to identify what the likely equilibrium prices and quantities would be if operation and pricing were based on bids submitted in a market mechanism.

While market liberalization would help diminish legal disputes, there are some specific features of the Brazilian electricity market that raise concerns regarding the degree of competition that may be expected in the Brazilian electricity market:

- The concentration of ownership;

- The large share of power plants that are jointly managed under shared ownership by various economic groups (i.e. shareholders);

- The operational interdependencies of hydropower plants on the same water course; and

- The fact that the system is 'energy constrained' by the hydro-inflow conditions, which implies that the market structure varies from year to year due to the occurrence of different hydro-inflow scenarios (i.e. exceptionally dry year, exceptionally wet year, El Niño and La Niña).

Thus, it is important that the simulation model takes into consideration these main features of the Brazilian electric power industry.

Simulations not only enable the exploration of expected market equilibrium in a liberalized market, but also the evaluation of the impact of various changes, such as:

- Price elasticities changes, which are likely to increase given the technological changes underway (such as the emergence of the 'internet of things' and implementation of 'smart grids') that will enable more refined demand-side management;

- The split up of the dominant market player, state-owned company Eletrobras, into five independent firms (Eletrobras, Chesf, Eletronorte, Eletrosul and Furnas); and

- Different demand conditions (occurrence of above or below-average demand growth rates).

To address these issues, this paper is structured in six sections including to this introductory one. The second section provides the context of the Brazilian electric power industry. The third describes the methodology employed. The fourth section describes the simulation model employed. The fifth summarizes the results and the sixth section presents the conclusions of this study.

\section{CONTEXT}

\subsection{IMPETUS FOR CHANGE}

Although the mid-1990s sectorial reforms introduced competition in the commercialization of wholesale electricity supply contracts in Brazil, the system 
continued being operated as a 'tight pool', with centralized operation determined by the System Operator. Given that most of the power in Brazil's electric system is derived from hydroelectric power plants, authorities deemed centralized dispatch essential to assure the synergetic gains from coordinated hydroelectric operation. Complex stochastic dynamic programming techniques are employed by the System Operator to determine the intertemporal opportunity cost of water stored in the hydroelectric reservoirs to optimize hydrothermal dispatch. Thus, operation and spot market pricing continue to be centrally determined.

This market arrangement in which power producers commercialize long-term supply contracts at their own risk, while subjected to the dispatch determined by the System Operator has become increasingly problematic. This delicate arrangement requires a high degree of stability, transparency and replicability in the operational procedures. This has been sought out by detailed Network Procedures (Procedimentos de Rede) that govern the System Operator's actions and by the use of official computer models to determine spot market pricing and dispatch. These official computer programs are made available to all market participants to enable them to model and simulate system operation. Nevertheless, changing system characteristics, altered reliability criteria and increasing disagreements regarding input variables (such as projected demand growth and projected generation and transmission capacity expansions) have prompted an increasing number of disputes and litigation. Many market participants have begun to question if it would not be better to migrate to a system in which operation and spot market prices are based on bids submitted by market players in a day-ahead market, as is the case in most electric power markets.

The main competitive concern that arises when considering the liberalization of the Brazilian electric power market is the risk of abuse of market power by hydropower producers.

Thermal power producers are not as much of concern because they represent a relatively small share of the market, and because market-monitoring schemes developed in other electric systems could be put in place to prevent market power abuse. The identification of market power abuse by thermo power producers is much simpler than for hydropower producers, since thermo power technologies are relatively standardized, enabling policy makers to rely on third-party information sources on typical plant productivity, fixed and variable costs, and market fuel prices.

In contrast, hydropower plants are typically very different from one another. Dams and turbines are tailor made for each particular hydro site. In addition, the marginal costs of hydropower plants with regulation reservoirs are determined by the plant's opportunity costs, which depend on one's outlook with regard to futures supply and demand conditions. These features make it very difficult to characterize market power abuse. 


\subsection{MARKET STRUCTURE}

\subsubsection{MARKET CONCENTRATION}

The first factor that needs to be taken into consideration in assessing competition is market structure, for which the starting point is the analysis of market concentration.

Farrell and Shapiro (1990) demonstrate that in a market for a homogeneous good, in Cournot competition, the price mark-up is positively correlated with market concentration. This provides the foundation for antitrust authorities' horizontal merger analysis.

The intuition behind the model is the basic tradeoff the firm is faced when it restrains supply: as firm $i$ reduces its own supply, it decreases aggregate supply $\left(\sum_{j \in F} q_{j}\right)$, which increases the market price, but also lowers its sales.

$$
\pi_{i}\left(q_{i} \mid \sum_{j \neq i} q_{j}\right)=\left[P\left(q_{i}+\sum_{j \neq i} q_{j}\right)-c\right] q_{i}
$$

In equation (1), $\pi_{i}\left(q_{i}\right)$ is the profit of firm $i$ as function of its own supply $\left(q_{i}\right)$, given the amount supplied by its competitors $\left(\sum_{j \neq i} q_{j}\right), P(\cdot)$ is the inverse demand function, and $c$ is the marginal cost of production.

The net effect on the firm's profits depends on its market share: the 'price effect' becomes greater as the player's market share increases, while the 'sales effect' prevails for players with small market shares.

Analytical models of oligopolistic competition, such as that presented in Willig (1991), demonstrate that the price mark-up is positively correlated to market concentration measured by the Herfidahl e Hirschmann Index (HHI), ${ }^{2}$ and inversely correlated to the price-elasticity of demand:

$$
\frac{P\left(\sum_{i} q_{i}\right)-c}{P\left(\sum_{i} q_{i}\right)}=\frac{H H I}{\varepsilon}
$$

In equation (2):

$P($ ) is the inverse demand function (gives the market price as a function of aggregate quantity supplied);

$q_{i} \quad$ is the quantity supplied by player $i$;

2 The Herfindahl-Hirschman Index (HHI) is defined as the sum of the squares of the market shares, $s$ (in percentage terms), of each of market player $i: H H I=\sum_{i} s_{i}^{2}$, thus the index varies from 0 (perfect competition) to 10,000 (monopoly). 
$c \quad$ is the marginal cost; and

$\varepsilon \quad$ is the price-elasticity of demand.

Antitrust authorities use the HHI as a guide to focus their efforts in the analysis of mergers and acquisitions. ${ }^{3}$ The limits typically adopted to classify horizontal mergers are:

- An $H H I$ below 1,500 to be 'unconcentrated' ;

- An $H H I$ of 1,500 to 2,500 to be 'moderately concentrated'; and

- An $H H I$ of 2,500 or greater to be 'highly concentrated'.

These are useful guidelines for an initial evaluation of potential assessment of competition in a liberalized electric power market.

To ascertain the level of market concentration of hydropower generation in the Brazilian electric system three structural features of hydro generation are appraised:

- The installed capacity;

- The maximum production capacity of the 'controllable hydropower' plants given average hydro inflows; and

- The reservoir storage capacity.

While the hydropower plant capacity to meet instant demand is given by its installed capacity, the more relevant constraint for hydropower generation in a longer time frame is the amount of energy it can produce given a particular hydro inflow scenario. Thus, the second feature listed above - maximum production capacity of the 'controllable hydropower' plants - seeks to assess this 'energy constraint' rather than the 'capacity constraint'.

The term controllable hydropower refers to hydropower plants with reservoir storage capacity sufficient to sustain the hydropower plant's 'firm energy' production for at least one month with no additional hydro inflows.

The remaining hydropower plants are termed run-of-river hydropower plants. Although they may have sufficient reservoir storage capacity to modulate production on a daily or weekly basis, their seasonal production is determined by their respective hydro inflows. Thus, run-of-river hydropower plants do not cause major competitive concerns, because their production is largely uncontrollable by the owner of the power plant.

Reservoir storage capacity is expressed in terms of the amount of energy that can be produced with the amount of water storable in the respective hydropower reservoir.

3 For example, the HHI criteria used to focus horizontal merger analysis of the U.S. Department of Justice (2010) and that of the Conselho Administrativo de Defesa Econômica (2016), Brazil's competition authority. 
Reservoir storage capacity is a strategic factor because it determines the level of intertemporal arbitrage hydropower producers can engage in.

The current market is heavily concentrated. Eletrobras, the Federal state-owned holding company, and its fully-controlled subsidiaries - Furnas, Chesf, Eletronorte and Eletrosul - own $57.1 \%$ of the total hydro reservoir storage capacity and $43.8 \%$ of the total installed hydropower generating capacity. The concentration is significantly lower, however, if the Eletrobras subsidiaries were to operate independently from each other and the holding company.

Thus, the Herfindahl-Hirschman Index (HHI) has been calculated for each of these three dimensions, considering two situations:

- Eletrobras Consolidated, in which, all power plants under the Eletrobras umbrella are considered to be operated in a coordinated manner by the holding company; and

- Eletrobras Split-Up, in which, the four major Eletrobras subsidiaries are assumed to operate as independent entities.

Figure 1 shows the HHI for the shareholdings of hydro generating installed capacity, hydro reservoir storage capacity and maximum production capacity of controllable hydropower plants in Brazil, considering long-term average hydro inflows.

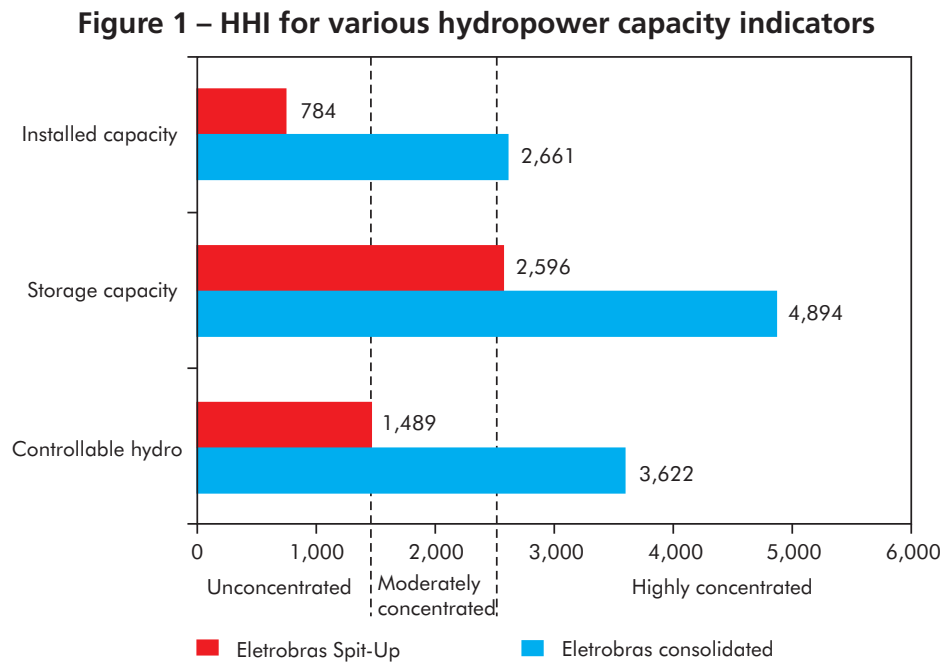

\footnotetext{
Note: The HHI for each hydropower structural feature were computed considering the respective level of control held by the respective shareholders of the hydropower plants (as explained in section 2.2.2). The technical data regarding the hydropower plants was obtained from Brazil's electric power regulator, Agência Nacional de Energia Elétrica (ANEEL, 2016a). The shareholdings of each power plant was also obtained from ANEEL (2016b). The data was accessed in August 2016 and updated to consider State Grid's acquisition of CPFL; CTG's acquisition of Ilha Solteira and Jupiá hydropower plants; and the hydropower plants previously owned by Duke Energy, that were also acquired by CTG.
}

Source: Authors' calculation based on data from ANEEL (2016a) and ANEEL (2016b). 
The analysis shows that splitting up the four Eletrobras' subsidiaries impacts market structure considerably, shifting the market from the 'highly concentrated' range to the 'unconcentrated', or very close to the 'moderately concentrated' range. Thus, market concentration is an important structural factor to be considered by policymakers looking ahead at the prospects of further liberalization of the Brazilian electric power market.

\subsubsection{SHARED OWNERSHIP}

The second factor that should be taken into consideration in assessing competition is the shareholder structure of firms, since shared ownership can significantly impact competition dynamics.

Salop and O'Brian (2000) point out that partial ownership can affect competition in various ways. The key insight of their analysis is the distinction between 'financial interest' and 'corporate control', in which the former refers to division of the proceeds of the firm's profits and the latter refers to the ability to influence the decision-making process. Their analysis shows that when there is shared ownership, discrepancies between the level of control and the level of financial interests arise, which alter the market competitive dynamics.

In a situation in which the financial interests are greater than the degree of control in the acquired firm, the acquisition incents the firm to reduce the supply of the power plants under its control because the 'price effect' is amplified by the additional revenues from the sales obtained from partially acquired firm.

On the other hand, when the control is larger than the financial interest in the acquired firm, the firm seeks to raise market prices by reducing production of the acquired firm. This is because the negative 'sales effect' is disproportionately borne by the other shareholders, while the firm reaps increased revenues from the sales of its remaining power plants at higher market price.

Shared ownership has been a major concern in various antitrust cases in Brazil. For example, Garcia and Farina (2013) analyze the impact of shared ownership in the Brazilian ready-mixed concrete industry and conclude that partial ownership does influence competition and, therefore, minority shareholdings in rival firms should be considered in the analysis of horizontal mergers.

Shared ownership is pervasive in Brazil. Lazzarini (2011) argues that crossownership between major corporations is common in Brazil due to what he refers to as 'relational capitalism' (capitalismo de laços). It is the outgrowth of an economy in which the government has always played a central role.

The Brazilian electric power industry is no exception: most of the large hydropower plants built in the last two decades have been developed in consortia with state-owned companies or companies with close ties to the government. 
The current regulatory framework of the electric power facilitates sharedownership. When a power plant is granted a license to operate by the Ministry of Mines and Energy, it is attributed a 'Firm Energy', which caps the maximum amount of energy it may sell in long-term contracts. The Firm Energy (Garantia Física) is the amount of energy the power plant is expected to reliably supply to the system. ${ }^{4}$ Since dispatch and spot market pricing are centrally determined, shareholders of the power plant need only concern themselves with the commercialization of their respective share of thepower plant's Firm Energy.

However, if bid-based dispatch is to be adopted, shared-ownership will become very relevant, since shareholders will then have to determine how each hydropower plant is to bid in the day-ahead market.

Figure 2 shows the ownership linkages of Brazil's major hydropower plants. The squares represent the major shareholders, the circles represent the run-of-river hydropower plants and triangles represent the hydropower plants with regulation reservoirs. The size of the icons of the hydropower plants is proportional to their installed capacity and the size of the squares is proportional to the sum of the shareholder's share of hydropower capacity in its portfolio.

The figure demonstrates that cross-ownership is pervasive. There are 84 strategic shareholders (shareholders with at least a 5\% stake in each company stock), most having subsets of hydropower plants jointly owned with various other shareholders.

Thus, shared ownership is a factor that should be taken into consideration when evaluating competition in the electric power market if bid-based dispatch is to be adopted.

4 The computation of a power plant's Firm Energy is based on simulations taking into consideration its systemic value (i.e. amount of energy the power plant reliably aggregates to the system weighted by the value of the electricity to the system at each period). 


\section{Figure 2 - Major shareholder ownership of hydropower generation}

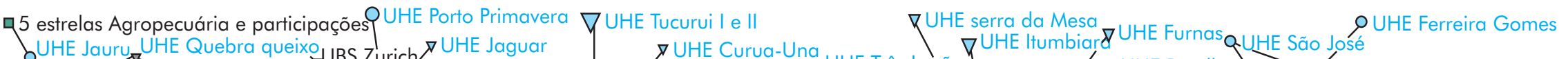

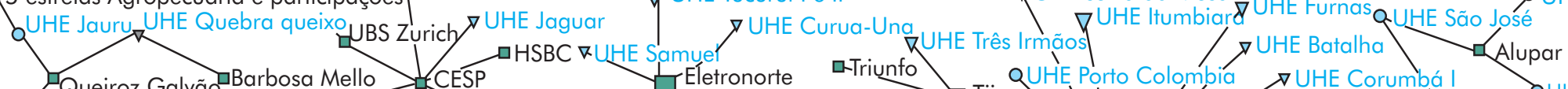
OUHE S. Clara $(\mathrm{MG})_{\square \text { Secretaria a Fazenda do Est. de SP }}$ QUHE Cachoeira Dourada LEMAE — Metro GTarpon Q Celqenerg $\square$ Enel $\rightarrow$ Arcelor Mittal Bras II $\square$ Ande OUHE Guilman Amorim OUHE Samarco Mineração OUHE Xingo PUHE Sobradinho OUHE Dardanelos

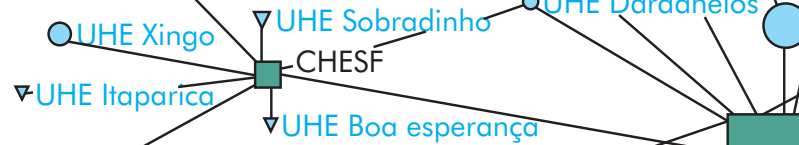
OUHE Complexo Paulo Afonso aGoverno Estado S. Catariner Real grandeza aIVESTPREV

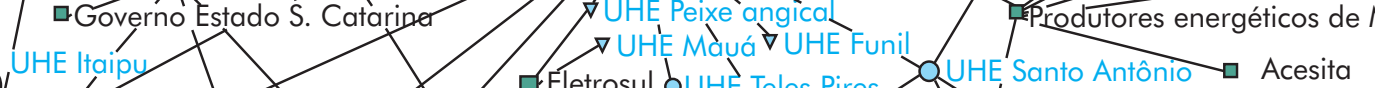

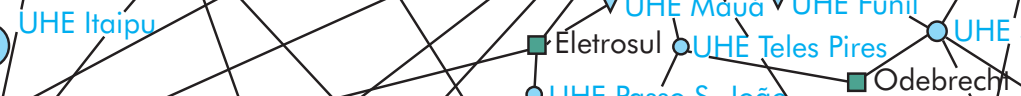
Eletrosul QUHE Teles Pires Acesita

aSecretaria de Estado de Fazenda do Distrito Fed Eletobras Caixa de Previdênciá. do B. Brasio UHE Baguar Andrade Gutierrez

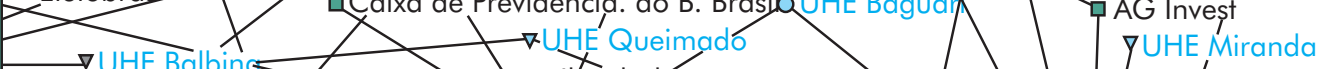

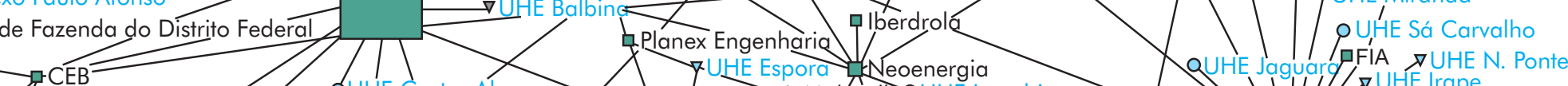
a Serveng Civilsan aTerracap UHE Corumbá IVOUHE Jirau Camargo Correa

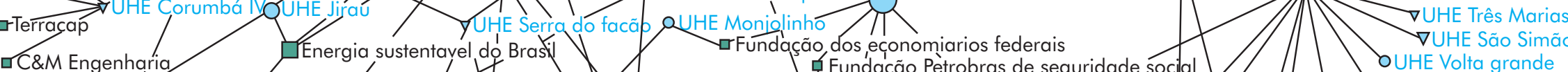

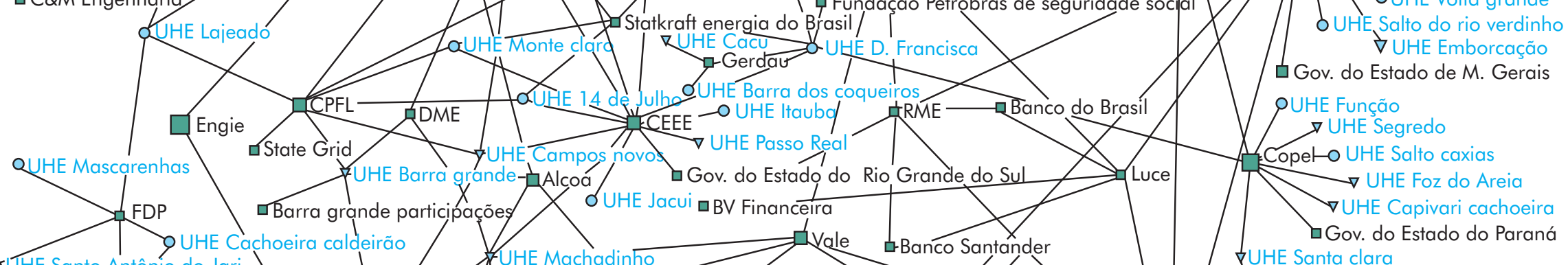
QUHE Salto CTG -Ro Verde nergia

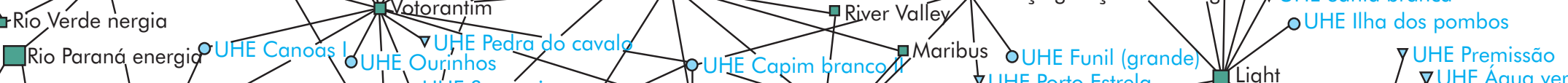
$\nabla$ UHE llha Solteira OUHE Canoas II bUHE Sopragi

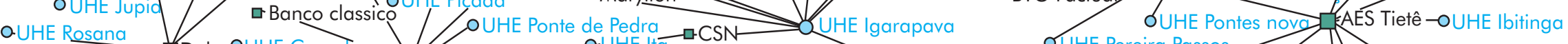

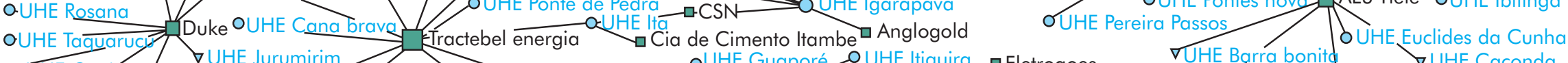
$\nabla$ UHE Capivard $\nabla$ UHE Jurumirim Javantes $\nabla$ UHE Salto Santiago OUHE Passo Fundo QUHE Guaporé O UHE Itiquira a-Eletrogoes VUHE Barra bonito

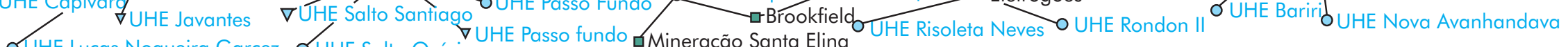




\subsection{OPERATIONAL INTERDEPENDENCIES}

The third factor that needs to be considered in the assessment of competition in the Brazilian electric power industry is the operational interdependency that may exist between hydropower plants. This is the factor that most concerns Brazilian electric power specialists regarding the adoption of bid-based dispatch. Many hydropower plants in Brazil are located on the same waterways, such that the operation of hydropower plants downstream depends on how the upstream hydropower plants are operated. This implies that there may be externalities in hydropower plant operation. These externalities give rise to the same type of discrepancies between control and financial interests discussed in the previous section due to shared ownership: the upstream hydropower plant can control not only its own production but also that of downstream run-of-river hydropower owned by another market player.

Figure 3 shows a schematic representation of the hydropower plants in Brazil. The river flows are from top to bottom. The triangles represent hydropower plants with regulation reservoirs (controllable hydropower plants) and the circles represent runof-river hydropower plants.

Notice that there are numerous situations in which run-of-river hydropower plants are located directly downstream from controllable hydropower plants. In these cases, the medium- to long-term (horizon of several months or more) production of the downstream hydropower plant is largely dictated by the operation of the upstream controllable hydropower plant, regardless of ownership structure of the respective hydropower plants. Thus, the same type of dichotomy between financial interests and control that arise from shared ownership (discussed in previous section) can arise from operational interdependencies of hydropower plants on the same waterways.

Total hydropower production capacity considering the long-run average hydro inflows is 68.5 gigawatts-average $\left(\mathrm{GW}\right.$-avg). ${ }^{5}$ The composition of hydropower generation capacity is the following:

- 26.1 GW-avg is from controllable hydropower plants (hydropower plants with regulating reservoirs), which corresponds to $38 \%$ of the total hydropower capacity; and

\footnotetext{
The unit of measurement, GW-avg (gigawatts-average), is often used in the Brazilian electric sector. It represents the average amount of GWh (gigawatt-hours) produced during a particular period. In this case, we consider yearly averages, so that $1 \mathrm{GW}$-avg corresponds to $8,760 \mathrm{GWh} /$ year $(8,760$ being the number of hours in a year).
} 
- $42.4 \mathrm{GW}$-avg is from run-of-river hydropower plants, which corresponds to $62 \%$ of total hydropower capacity.

Although the run-of-river hydropower plants have no direct control over hydro flows, a large share is controllable by hydropower plants upstream:

- $19.6 \mathrm{GW}$-avg (46\% of run-of-river hydropower plants) is downstream controllable generation, in other words, production from run-of-river hydropower plants whose production is determined by the hydro outflow from controllable hydropower plants upstream; and

- $22.9 \mathrm{GW}$-avg (54\% of run-of-river hydropower plants) is uncontrollable generation, which is the hydro generation that is not controllable by any player (i.e. production is dictated by the natural hydro inflows).

This means that, although hydropower plants with regulating reservoirs produce only $38 \%$ of the energy they determine $71.4 \%$ of total hydropower generation, while $28.6 \%$ is uncontrollable (i.e. determined by the state of nature). 


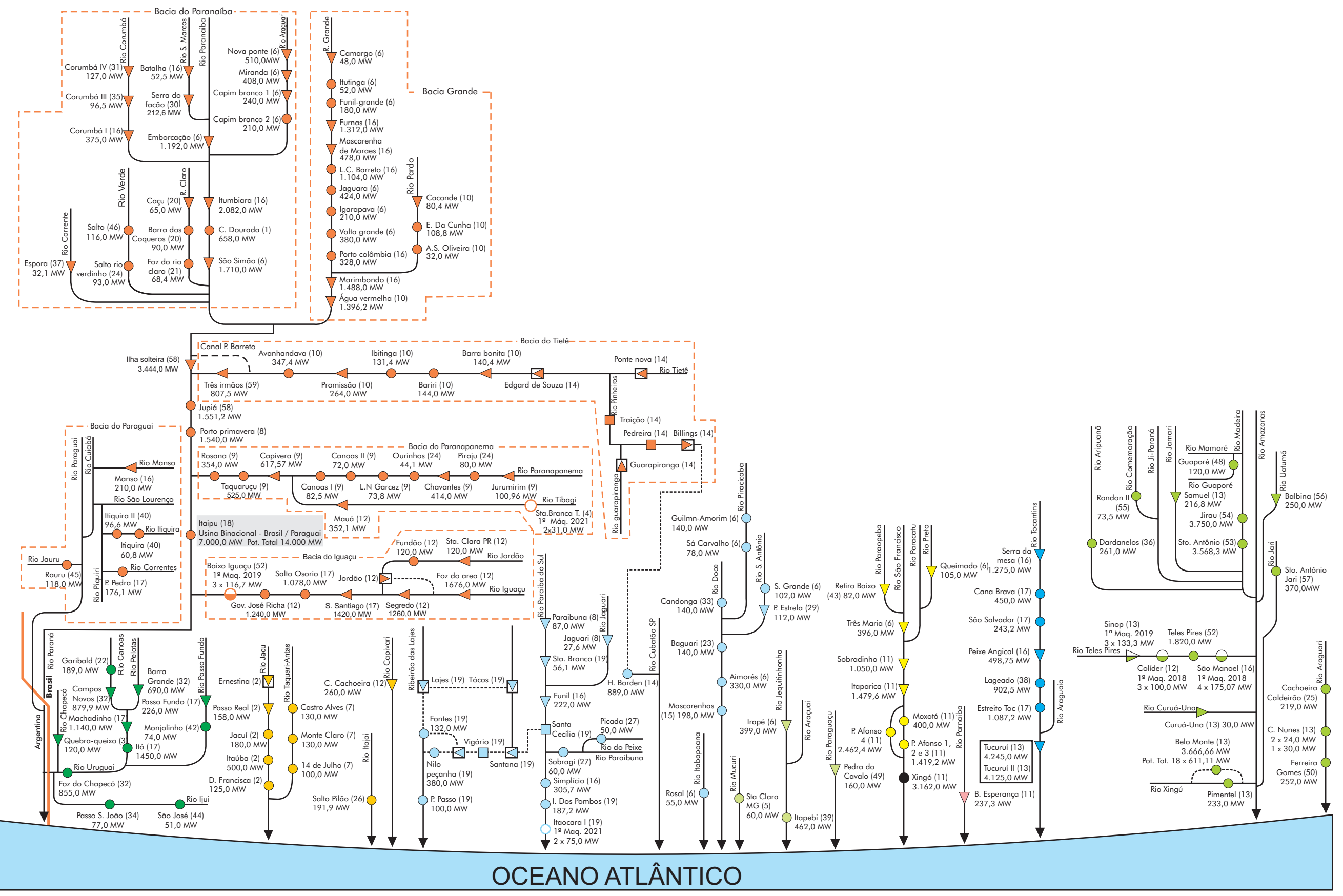




\subsection{HYDRO INFLOW SCENARIOS}

The fourth factor that needs to be considered in Brazil's predominantly hydroelectric system is to what extent hydro inflow scenarios alter market structure from year to year.

The most relevant capacity constraint of hydrogeneration (in the medium- to long-term horizon) is the maximum production capacity given the particular hydro inflow scenario. Figure 4 shows the aggregate annual hydro inflows for the Brazilian electric power system. The annual Natural Hydro Inflows (Energia Natural Afluente - ENA $)^{6}$ vary substantially from year to year.

Figure 4 - Aggregate annual Natural Hydro Inflows and Firm Energy

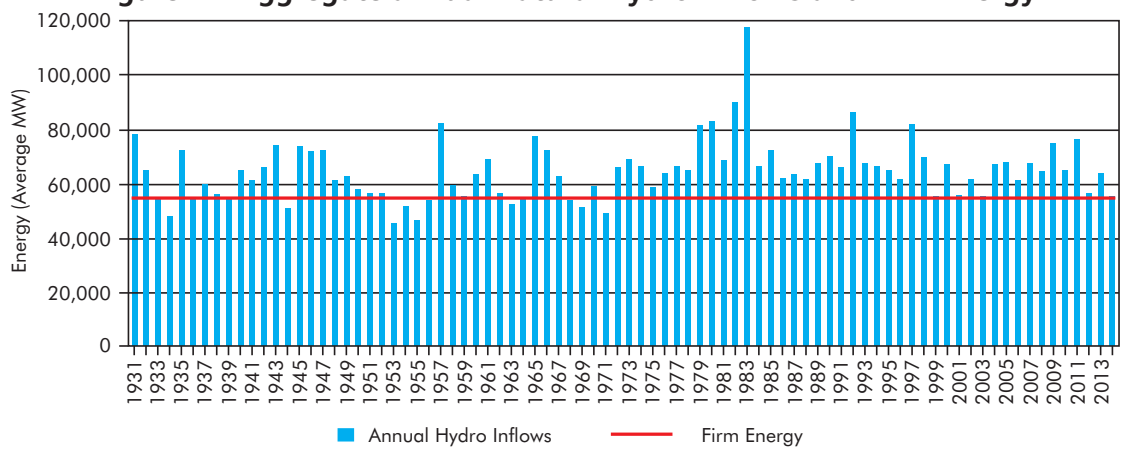

Source: Authors' elaboration based on data from ANEEL (2016a) and ONS (2017b).

For the most part hydro inflows are positively correlated between hydropower plants, but hydro scenarios do not impact all hydropower plants equally and in some hydro scenarios, some hydropower producers may be benefited while others are harmed.

Figure 5 illustrates how the El Niño and the La Niña climatic phenomena affect various players. El Niño ${ }^{7}$ generally benefits most players (increasing hydro inflows),

6 The 'Natural Hydro Inflow' is the amount of electricity that can be produced by all hydropower plants with the water available maintaining the hydro reservoir levels unchanged. The water inflows of a given waterway are converted into units of electric power by computing the amount of energy that could be produced if the flow of water were channeled through the hydro turbines of all hydropower plants on the waterway multiplied by their respective productivity. The hydro power plant's productivity depends fundamentally on three variables: (i) the head (difference in height between the source and the water's outflow); (ii) the volumetric flow rate of water flowing through the turbine; and (iii) the turbine efficiency. In this paper, the natural hydro inflows were computed assuming storage in all hydro reservoirs is fixed at $65 \%$ of capacity.

7 The evaluation took into consideration the average hydro inflows from the years of occurrence of 'strong El Niño' phenomena: 1939-1941, 1957-1959, 1972-1973, 1982-1983, 1990-1993, and 1997-1998. The identification of the El Niño years was based on information from Instituto Nacional de Pesquisas Espaciais (INPE, 2017). 
but for a few players it actually results in a fall in hydro inflows. The five most benefited players (in absolute terms) on average experience a 10 to $18 \%$ increase of hydro inflows in El Niño years, and some smaller players actually experience more than $30 \%$ gains. At the bottom of the scale, one observes players that experience no gains or even losses.

La Niña ${ }^{8}$ generally harms hydropower producers in Brazil. Although a few may experience a few percentage points gain, most suffer a decrease in their hydro inflows. The five largest losses (in absolute terms) experience an average drop of 7 to $10 \%$ in La Niña years.

This brief analysis indicates that changing hydro inflow scenarios has an influence on players' production capacity in very different ways, thus having the potential to significantly affect market competition dynamics.

8 The evaluation took into consideration the average hydro inflows from the years of occurrence of 'strong La Niña’ phenomena: 1938-1939, 1949-1951, 1954-1956, 1973-1976, 1988-1989, and 2007-2008. The identification of the La Niña years was based on information from INPE (INPE, 2017). 
Figure 5 - Deviation from long-term average hydro inflows

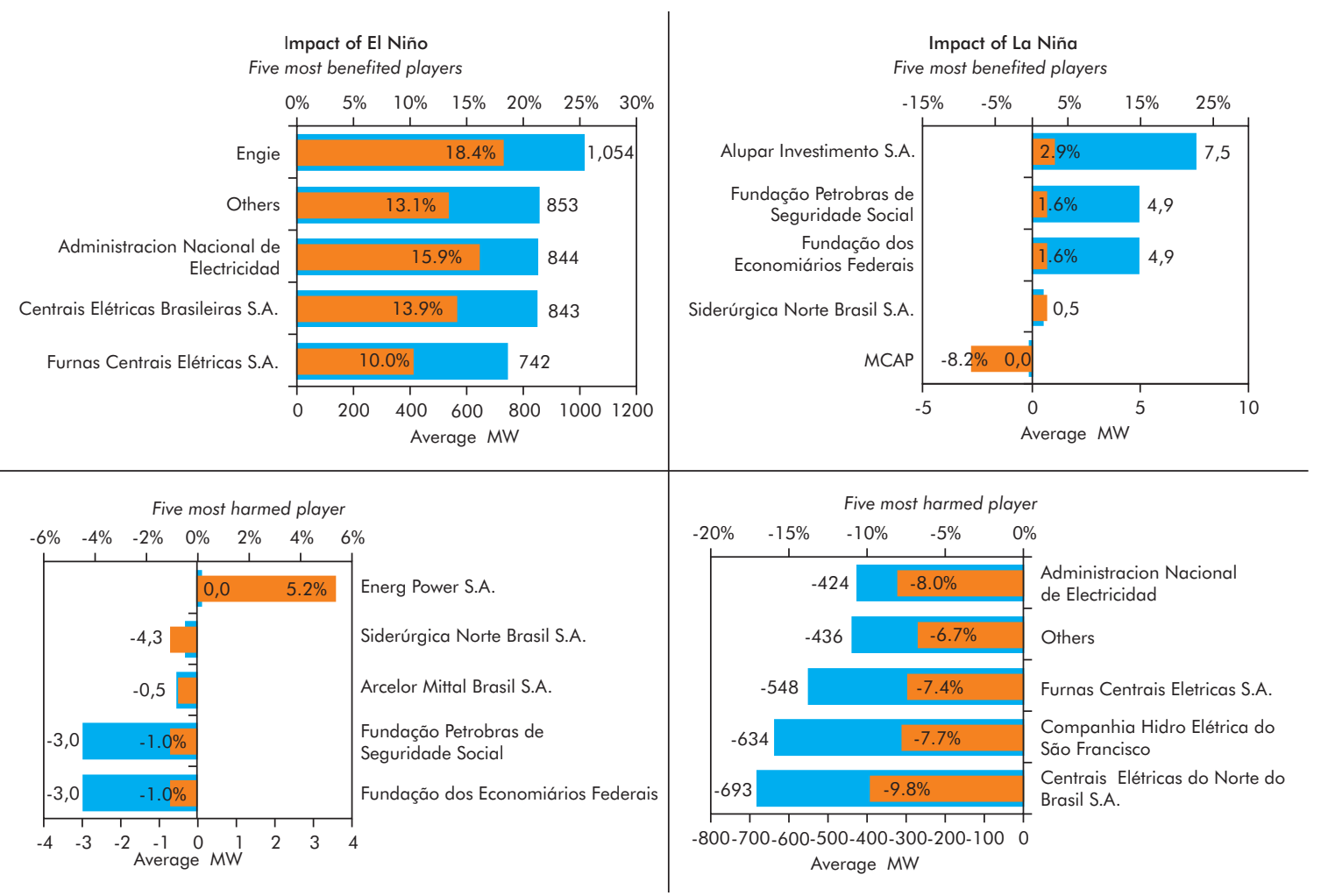

Source: Authors' elaboration based on data from ANEEL (2016), ONS (2016b) and INPE (2017). 


\section{THE METHODOLOGY}

\subsection{OVERVIEW}

To capture the four major competitive concerns (market concentration, sharedownership, operational interdependencies, and changing structure due to hydro inflow scenarios), the simulation must take into account:

- The relevant economic agents (market players), which are the major shareholders in this context;

- The disparities between each players' level of control and financial interest in each power plant of his or her portfolio due:

- To their respective shareholding structures; and

- To the operational interdependencies between hydropower plants; and

- The change in medium to long-term supply capacity of hydropower plants in different hydro inflow scenarios.

The assumption is that each shareholder determines the aggregate production desired from all the hydropower generation under their control, considering the revenue sharing derived from all hydropower plants in their portfolio.

The players' (shareholders) production decision is made seeking to maximize their profits. Each player makes his or her production decision taking into the consideration his or her conjecture of the remaining market players'production decisions.

Before one can start modeling the market, they must establish a methodology to quantify the level of control and financial interest resulting from the shared ownership and from operational interdependencies between hydropower plants. The methodology employed in this paper is presented in the following section.

\subsection{QUANTIFICATION}

To model the competitive effects of the asymmetries due to shared ownership and operational interdependencies between hydropower plants, it is necessary to quantify the discrepancies between the degree of control and financial interest of each player.

The financial interest of a shareholder is easy to evaluate since it is proportional to the amount of shares held in the firm, but control is more difficult to assess. 


\subsubsection{SHARED OWNERSHIP}

In firms with no majority shareholder (i.e. in which all shareholders have less than $50 \%$ of the firm's shares), how can one measure the shareholder's degree of control?

The shareholder's control depends on how essential its participation is to form a winning coalition. Various mathematical methods have been developed to measure control. In this paper, we utilize the method developed by Banzhaf (1965). ${ }^{9}$ His methodology consists of the measurement of the proportion of coalitions in which the participation of a particular agent is critical to ensure a particular outcome.

Mathematically, one can express the Banzhaf Index as follows: in a game of $N$ players, there are $2^{N-1}$ coalitions that can be formed (excluding a unanimity). Each player $i$ owns a share $w_{i}$ (voting weight), such that $0<w_{i}<1$. Considering that a simple majority is necessary to determine an outcome, any player with a share $w_{i}>.5$ will have full control, which implies the player's Banzhaf Index will be $B_{i}=1$. When no player has full control, one can identify the number of winning coalitions that can be formed, namely a subgroup of players in the market, $T \subset N$, such that $\sum_{j \in T} w_{j}>.5$. Player $i$ is considered 'critical' in a winning coalition if his or her withdrawal results in the coalition's aggregate share dropping below .5. If $\eta_{i}$ is the number of winning coalitions in which player $i$ is critical, then the Banzhaf Index can be expressed as:

$$
B_{i}=\frac{\eta_{i}}{2^{N-1}}
$$

The remaining pulverized shares not held by the 'major' shareholders identified in the study are aggregated in the 'Others'. The computation of the Banzhaf Index to measure the degree of control can be distorted by this aggregation. While the share of the company in the hands of shareholders in the 'Others' category can be large, the degree of control of the individual stockholders in this category is negligible, because the individual shareholders that make up the group take their decisions independently. To minimize this distortion, we have subdivided the 'Others' category when calculating the Banzhaf Index to the limit allowed by the algorithm utilized. ${ }^{10}$

9 Banzhaf (1965) developed his methodology to demonstrate that attributing weights to delegates in the legislature proportional to the number of voters in their respective districts does not ensure equal representation in the legislature. Thus, he did not refer to his index as a measure of 'control', but rather of 'legislative power'. Despite the different terminology, Banzhaf's 'legistlative power' meant the ability to affect outcomes, which is equivalent to what refer to as 'control'.

${ }_{10}$ The algorithm we used to compute the Banzhaf Index could take into account up to 63 shareholders, so we equally partitioned the share of the 'Others' category in the remaining vacant slots available in the algorithm developed by de Vries (2016). 


\subsubsection{HYDROPOWER GENERATION INTERDEPENDENCIES}

To model the asymmetries in the financial interest and control of hydropower generation, one can classify the hydropower generation of each player into four categories:

$Q_{i}^{c}$ Controllable generation - electricity produced by the players' share of controllable hydropower plants in their portfolio;

$Q^{c_{i}}$ Downstream controllable generation - electricity produced by downstream run-of-river hydropower plants that belong to another player, but whose production is determined by the player's upstream controllable hydropower plant production decisions;

$Q_{i}^{c_{j}}$ Downstream generation controllable by others - electricity produced by downstream run-of-river hydropower plants that belong to the player, but whose production is function of an upstream controllable hydropower plants controlled by other players; and

$Q_{i}^{n c}$ Uncontrollable energy - electricity produced by the player's share of the runof-river hydropower plants whose hydro inflows are not controlled by any player.

With this division, it is possible to determine the control and financial interest of the market players in hydropower generation.

\section{THE SIMULATION MODEL}

\subsection{COURNOT COMPETITION}

The Cournot quantity-setting paradigm is an appropriate approach to simulate electric power markets. Although day-ahead power markets typically submit price and quantity bids, the Cournot paradigm represents market dynamics better than the Bertrand paradigm for various reasons.

First, because the market mechanism typically employed determines a single spot price equal to the marginal bid for each time and space interval. Thus, all power producers whose bids are accepted for a particular spot-market-pricing interval are paid the same price. In other words, the dominant philosophy governing the design of electric power markets has been that of increasing time and space granularity to the point that all goods commercialized (at the given market delimitation of time and space) are homogeneous.

Second, because power producers supply is constrained to their installed capacity and, in the case of renewables, to the availability of the natural energy resource (such 
as hydro inflows, wind, biomass, and solar radiation). Thus, as Kreps and Scheinkman (1983) point out, even when players submit price bids, if the players' supply is constrained by installed capacity limitations, market equilibrium tends to resemble the outcome of the Cournot model.

The use of the Cournot paradigm is not unusual for modeling electric power markets. Cournot simulation has been used to assess various electric power markets. The approach adopted in this paper draws from Borenstein and Bushnell (1999), and Borenstein, Bushnell and Knittel (1999) to simulate California's electric power market.

\subsection{DEMAND FUNCTION}

\subsubsection{FUNCTIONAL FORM OF DEMAND}

In the simulations, we adopt two different functional forms for demand:

- linear demand; and

- constant-elasticity demand.

\section{Linear Demand}

The demand function considering a linear functional form can be expressed by:

$$
Q(P)=a+b P
$$

or by the inverse demand function:

$$
P(Q)=\frac{Q-a}{\left(\varepsilon \cdot \frac{Q}{P}\right)}
$$

One can build the inverse demand function considering:

- A market equilibrium point (a particular price and quantity observation: $P_{0}, Q_{0}$ ), which we refer to as the 'reference equilibrium'; and

- The estimated price-elasticity of demand: $\varepsilon=\frac{\partial Q}{\partial P} \cdot \frac{P_{0}}{Q_{0}}$.

Given these parameters, one can compute the slope of the linear demand function, $b=\frac{\partial Q}{\partial P}$, which is equivalent to:

$$
b=\varepsilon \cdot \frac{Q_{0}}{P_{0}}
$$


and the intercept, the constant $a$, which is equivalent to:

$$
a=(1-\varepsilon) \cdot Q_{0}
$$

\section{Constant-Elasticity Demand}

The demand function considering a constant-elasticity functional form can be expressed by:

$$
Q(P)=k \cdot P^{\varepsilon}
$$

and the inverse demand function by:

$$
P(Q)=\left(\frac{Q}{k}\right)^{\frac{1}{\varepsilon}}
$$

Given the price elasticity and a market equilibrium point $P_{0}, Q_{0}$, one can construct the demand function.

\section{Reference Equilibrium}

For the 'reference equilibrium', we adopted the average price of long-term contracts in Brazil's wholesale market, which is currently R\$205/MWh, ${ }^{11}$ and total demand, which is approximately $65 \mathrm{GW}$-average.

\section{Price elasticity}

We consider a price elasticity of -0.3 based on numerous econometric estimates: Abreu and Sant'Anna (2009); Andrade and Lobão (1997); Assunção, Rezende and Schutze (2015); Modiano (1984); and Schmidt and Lima (2004). Residential consumers have the lowest price elasticity, and industrial and commercial customers have the highest elasticities, but average aggregate price elasticity is around -0.3 .

This is a relatively low price elasticity and there is a general consensus that in the coming years demand should become more elastic as consumers become more aware of electricity prices. Furthermore, the 'Internet of Things' enables equipment to automatic adjust consumption in response to electricity price alterations, and small-scaledistributed generation technologies enable consumers to resort to self-generation.

11 The average cost of electricity contracted in the Brazilian electricity regulated market in Brazil is currently R\$ 204.84/MWh (Despacho 2796-Aneel, 19/10/2016). 


\subsubsection{THERMO POWER GENERATION}

Adding the marginal operating costs of each thermo power plant, ordered from lowest to highest costs, one obtains the aggregate thermo marginal cost function presented on Figure 6.

Figure 6 - Thermo generation aggregate marginal cost function

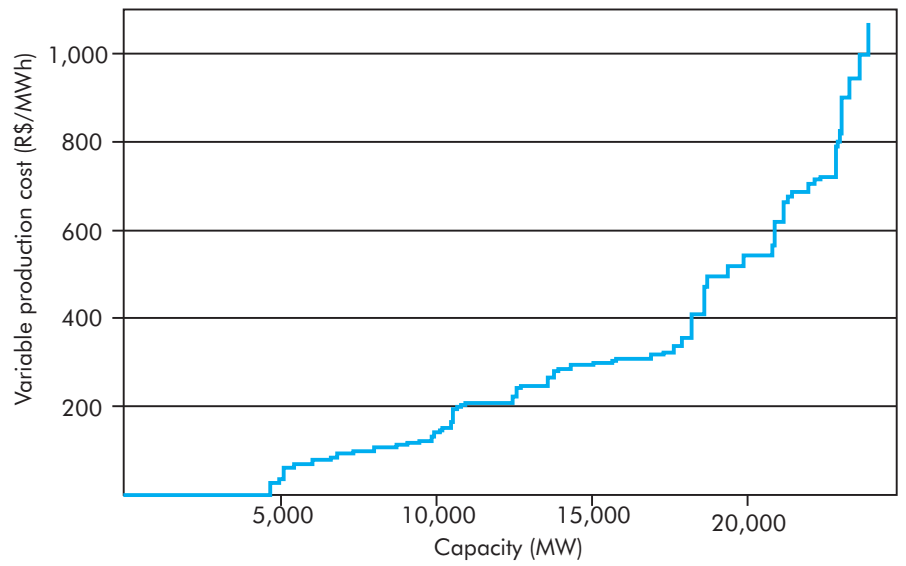

Source: Authors' elaboration based on data from ONS (2017b).

Notice that approximately the first 5,000 MW have no marginal cost. This is due to the fact that many thermo power producers have take-or-pay fuel provisions, which means that at least part of their fuel costs are fixed.

As explained in section 2.1, market power abuse by thermo power generation is not a major concern, because effective market-monitoring mechanisms can be used to identify and punish thermo power producers (using third-party cost information).

Thus, one can assume thermo power producers can be disciplined to behave competitively, acting as 'price-takers': offering all of their available capacity when prices are above their marginal costs, and none when prices drop below their marginal costs. In this situation, the aggregate thermo marginal cost function corresponds to the thermo power supply function.

\subsubsection{RESIDUAL DEMAND FOR HYDRO GENERATION}

By subtracting the thermo power supply function from the demand function, one can obtain the residual demand function for hydro generation, thus focusing the analysis exclusively on hydropower producers, which greatly simplifies the simulation process.

Residual demand functions for hydro generation considering the two demand functional forms, linear and constant-elasticity, are shown on Figure 7. 
Figure 7 - Residual Demand Function for Hydro Generation
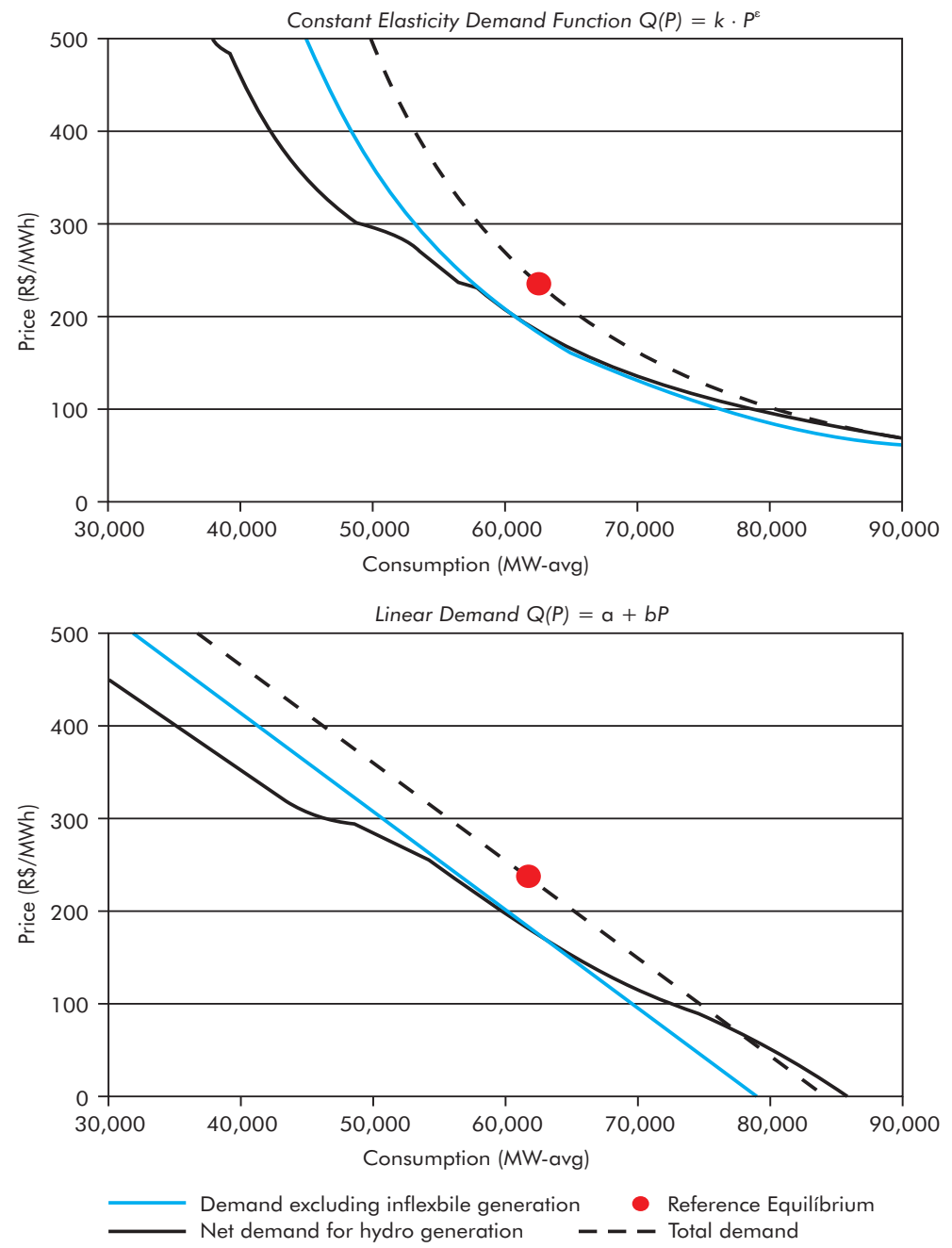

Source: Authors' elaboration.

The residual demand functions for hydro generation are built in two-step process.

First, the demand function is constructed considering the 'reference equilibrium' point, the price-elasticity, and the constants of the particular functional form to build the demand function.

Second, the thermo power supply function is subtracted to obtain the 'net demand for hydro generation'.

The figure also shows an intermediary step in which the supply from inflexible generation', that is, the must-run thermo power plants due to their take-or-pay provisions. 


\subsection{PROFIT FUNCTION AND CONSTRAINTS}

Hydropower production is governed by the availability of hydro inflows, which is the amount of water available for generation multiplied by the hydropower plant's productivity, and the hydropower plant's capacity limitations: installed capacity and storage capacity.

\subsubsection{CONTROL AND FINANCIAL INTEREST ACCOUNTING}

The structure of the hydropower producers profit maximization problem is quite complex because the asymmetries between financial interest and control vary in two dimensions:

- Due to corporate shareholdings of the various players in each hydropower plant; and

- Due to the operational interdependencies of run-of-river hydropower plants downstream from controllable hydropower plants.

The aggregation procedure adopted in this paper is the following:

- First: the production derived from run-of-river hydropower plants immediately downstream from controllable hydropower plants (considering the long-run average hydro inflows) is aggregated to compute the control multiple associated with each controllable hydropower plant;

- Second: the aggregate hydro capacity (given a particular hydro scenario) under control of each player is computed, utilizing the Banzhaf index. This includes the generation from the hydropower plants with regulating reservoirs and that of the run-of-river hydropower plants directly downstream;

- Third: each player's shareholdings in the respective hydropower plants is utilized to determine each player's share of aggregate revenues derived:

- from controllable hydropower plants under the player's control;

- from player's run-of-river hydropower plants directly downstream from the controllable hydropower plants; and

- $\quad$ from hydropower plants whose production is not controllable by any player.

One of the drawbacks of this simplified aggregation process is the loss of tractability of which run-of-river hydropower plants are impacted by which controllable hydropower plants. To reflect the specific operational linkages between each hydropower plant would increase the simulation complexity exponentially.

In this simplified representation, the hydro balance restrictions of the controllable hydropower plants and the production derived from run-of-river hydropower plants downstream from controllable hydropower plants do not take into account the precise hydro outflows of the respective upstream plant. Instead, the generation factor of all controllable hydropower plants, computed as the ratio of their total generation with respect to their total long-term average Natural Hydro Inflows. 


\subsubsection{HYDROPOWER INTERTEMPORAL OPTIMIZATION}

Given the fact that controllable hydropower plants can engage in arbitrage between periods, it is important that the simulation model considers intertemporal profit maximization. In the simulation, we adopt a two-period model, each equivalent to one year. In the first period, hydropower producers decide how much to produce given known hydro inflows and how much to store for the second period based on an expected hydro inflow distribution function. The idea is that day-ahead market pricing is done in conjunction with forward or futures contracting a year ahead to allow hydropower producers to coordinate intertemporal arbitrage in a time frame that fosters long-term sustainability of supply.

The future hydro inflow scenario is a major source of uncertainty that must be considered when making operational decisions. Players must decide how much to produce in the first period taking into consideration expected hydro inflows in the following periods. Given that the probability distribution annual hydro inflows is not symmetric, hydro variation is an important source of price asymmetry. This asymmetry is then exacerbated by the large variability of market prices: in adverse hydro inflow scenarios, prices tend to be very high and in favorable inflow scenarios prices are very low. If the hydro producer is bound to long-term contractual commitments, in low hydro inflow conditions, they will pay high prices to purchase energy to cover supply deficits. In high hydro inflow conditions, prices will be low, thus providing little additional income from the sale of supply surplus.

To capture the dynamics that may arise from the hydro inflow uncertainty, the model considers three equally probable hydro scenarios.

The three hydro scenarios considered in the second period are built based on the historical record. Figure 8 shows the aggregate annual hydro inflows in the system from 1934 through 2014.

Considering that hydropower producers are required to commit to long-term contracts, one must determine what target level of storage is desirable to define a steady-state operational policy. To define this policy, a first simulation is performed to determine the initial and final reservoir storage level. This first simulation considers the long-run average hydro inflows in the first period and three scenarios in the second, with a restriction that the stored energy in the hydro reservoirs in the end of the three second-year scenarios must equal the reservoir levels in the beginning of the first period. This is the 'steady-state policy case. Once the steady-state storage is determined, the remaining simulations consider a restriction that imposes that the beginning (of the first period) and ending (of the second period) reservoir levels must be equal to the level determined in the steady-state policy case. 
Figure 8 - Historical distribution of hydro inflows

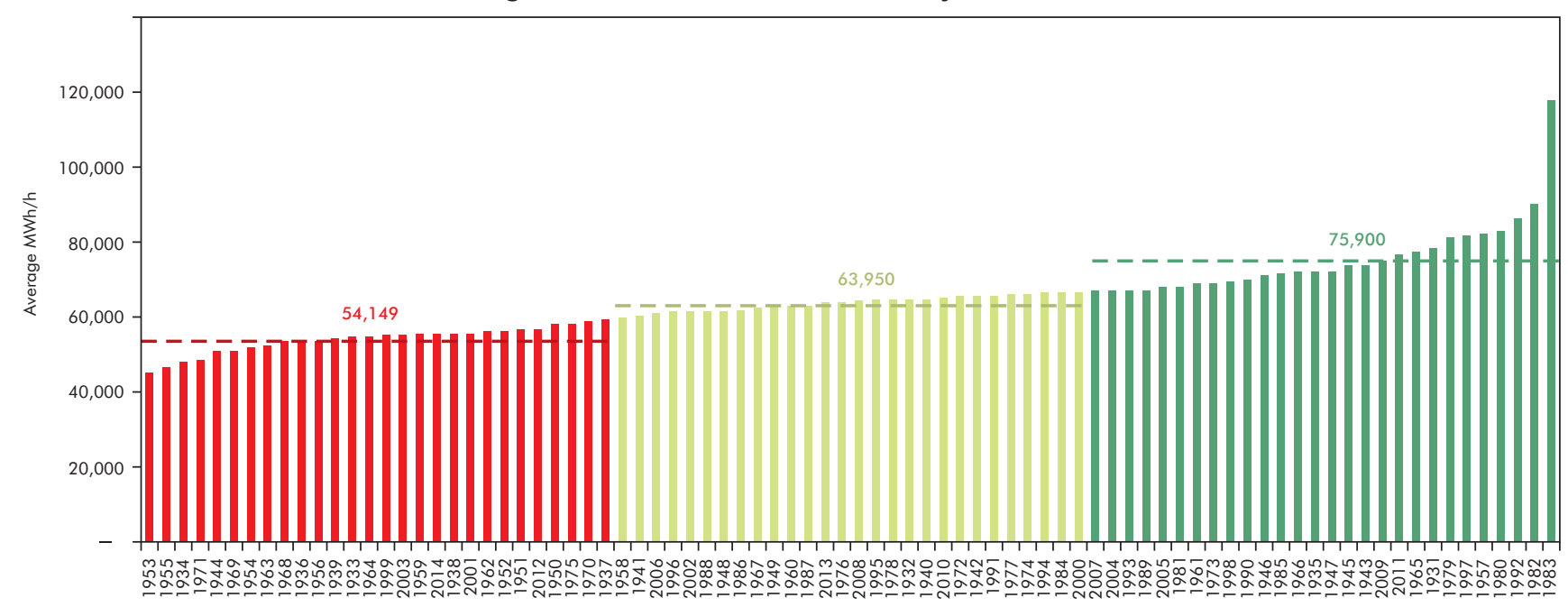

Source: Author's elaboration based on data from ONS (2017b). 
The profit maximization problem can those be expressed as:

$$
\left\{\begin{array}{l}
\quad \max _{Q_{i 1}^{c}, Q_{i 2 s, s \in\{h, m, l\}}^{c}}\left\{P\left[Q_{i 1}^{c} \cdot\left(1+M_{i}\right)+Q_{-i 1}^{c}\right]-c\right\} \cdot\left[s_{i} \cdot Q_{i 1}^{c}+\Theta_{1} \cdot Q_{i}^{c_{j}}+Q_{i 1}^{n c}\right] \\
+\frac{1}{3} \cdot \sum_{s \in\{h, m, l\}}\left\{P\left[Q_{i 2 s}^{c} \cdot\left(1+M_{i}\right)+Q_{-i 2 s}^{c}\right]-c\right\} \cdot\left[s_{i} \cdot Q_{i 2 s}^{c}+\Theta_{2 s} \cdot Q_{i}^{c_{j}}+Q_{i 2 s}^{n c}\right] \\
\text { s.t }: \\
0 \leq Q_{i 1}^{c} \leq B_{i} \cdot\left(A_{i 1}+V_{i 0}-V_{i 1}\right) \\
0 \leq Q_{i 1}^{c} \leq B_{i} \cdot \bar{Q}_{i}^{c} \\
0 \leq Q_{i 2 s}^{c} \leq B_{i} \cdot\left(A_{i 2 s}+V_{i 1}-V_{i 2}\right), \forall s=\{h, m, l\} \\
0 \leq Q_{i 2 s}^{c} \leq B_{i} \cdot \bar{Q}_{i}^{c} \text { and } \forall s=\{h, m, l\} \\
0 \leq V_{i 1} \leq \bar{V}_{i}, \\
V_{i} \leq V_{i 2 s} \leq \bar{V}_{i}, \forall i \text { and } \forall s=\{h, m, l\}
\end{array}\right.
$$

such that:

$Q_{i 1}^{c}$

$Q_{i 2 s, s \in\{h, m, l\}}^{c}$

$M_{i}$

$Q_{-i 1}$ and $Q_{-i 2 s} \quad$ is the electricity produced by all hydropower plants not controlled by player $i$, in each period ( 1 and 2 ), given state $s$;

$Q_{i 1}^{c_{j}}$ and $Q_{i 2 s}^{c_{j}} \quad$ is the electricity that belongs to player $i$ that is produced by run-of-river hydropower plants controlled by other players, in each period (1 and 2), given state $s$; 
$Q_{i 1}^{n c}$ and $Q_{i 2 s}^{n c} \quad$ is the electricity produced by the hydropower plants that cannot be controlled by any player that belongs player $i$, in each period (1 and 2), given state $s$;

$s_{i} \quad$ is the share of revenues player $i$ is entitled to receive given their shareholdings ofthe hydropower generation under their control;

$B_{i} \quad$ is the share of the controllable hydropower generation under control of player $i$,given by the Banzhaf index;

$\Theta_{1}=\frac{\sum_{i} Q_{i 1}^{c j}}{\sum_{i} \tilde{Q}_{i 1}^{c j}}$ and $\Theta_{2 s}=\frac{\sum_{i} Q_{i 2 s}^{c j}}{\sum_{i} \tilde{Q}_{i 2 s}^{c j}}$

is the overall generation factor of the controllable hydropower generation under control of other players (with respect to the long-term average hydro inflows), in each period (1 and 2), given state $s$;

$r$

$A_{i 1}$ and $A_{i 2 s}$

$V_{i 0}, V_{i 1}$ and $V_{i 2}$

$\bar{Q}_{i}^{c}$

$\tilde{Q}_{i}^{c}$

$\underline{V}_{i}$ and $\bar{V}_{i}$ is the intertemporal discount rate;

is the natural hydro inflow of player $i$ 's controllable hydropower plants, in each period ( 1 and 2 ), given state $s$;

is the volume of water stored (converted into units of energy) in the reservoir of hydropower plant $i$, respectively:

- at the beginning of period 1 (first year),

- at the end of period 1 , and

- at the end of period 2 (second year);

is the maximum output (installed capacity) of controllable hydropower plants controlled by player $i$;

is the output from player 's controllable hydropower plants produced with the long-term average Natural Hydro Inflow;

are the minimum and maximum volume of water to be stored in the regulating reservoirs controlled by player $i$.

\subsection{SIMULATION METHODOLOGY}

The simulation was programmed utilizing Wolfram's Mathematica 10. The CournotNash equilibrium concept is utilized to model the market, with each player maximizing profits by adjusting the controllable generation given:

- The player's capacity constraints;

- The other player's supply; and

- The residual inverse demand function for hydrogenation. 
The process is iterated repeatedly for all market players until the quantity supplied by each player from one iteration to another converges to a fixed-point.

The player classified as 'Others', which groups together the remaining pulverized shareholders (with less than 5\% stake in each power plant), is modeled differently than the remaining players. Modeling the grouping of these small shareholders as a single player would overestimate their market power (it would be as if they were colluding). Individually these market players most likely behave as price-takers, thus they have been modeled as arbitrating between periods shifting as much supply as possible to the period that provides the best price, bounded by their reservoir storage capacity limitations.

\section{RESULTS}

A series of simulations were conducted to evaluate market equilibrium if bid-based dispatch and pricing were adopted in Brazil. The results are summarized on Tables 1 and 2. Table 1 presents the results of simulations considering a linear demand and Table 2 presents the results of simulations considering constant-elasticity demand.

\subsection{DESCRIPTION OF THE SIMULATIONS}

The optimization problem in the Case $\mathbf{1}$ simulation is slightly different from the rest. This run was used to determine the steady-state policy for hydro reservoir storage. In this simulation, the initial and the final level of stored energy in the hydro reservoirs is a discretionary variable defined by the generators (control variable), with the restriction that they must be equal, considering the long-term average hydro inflows in the first period. The resulting storage level in this simulation was $35 \%$ of the total system's storage capacity. This parameter was then used as a restriction for the initial and final reservoir storage level.

The objective of this 'steady-state policy' is to ensure that the optimization process produces a sustainable policy that is consistent with long-term contractual supply commitments.

Case 2 is the base case simulation of the current market structure. It assumes the current market structure with the dominant firm, Eletrobras, making decisions as a single entity. The simulation indicates that if bid-based dispatch and pricing were adopted, first-period equilibrium prices would be slightly lower, R\$ 188.18/ $\mathrm{MWh}^{12}$ $(-8 \%)$, when hydro inflows are equal to the long-term average, and $30 \%$ higher than the 'reference equilibrium' price of R\$ 205/MW hin the second period $(+50 \%,+32 \%$ and $+8 \%$, respectively, in the 'high', 'medium' and 'low' scenarios).

12 The current exchange rate is approximately R\$3.30/US\$. 
Table 1 - Simulation results considering linear demand

\begin{tabular}{|c|c|c|c|c|c|c|c|c|c|c|c|c|c|c|}
\hline \multicolumn{7}{|c|}{ CASE SPECIFICATION } & \multicolumn{8}{|c|}{ RESULTS } \\
\hline \multirow{3}{*}{ Case } & \multirow{3}{*}{ Eletrobras } & \multirow{3}{*}{ Discount rate } & \multirow{3}{*}{$\begin{array}{c}\text { Price } \\
\text { elasticity }\end{array}$} & \multicolumn{2}{|c|}{ Reference equilibruim } & \multirow{3}{*}{$\begin{array}{c}\text { First period } \\
\begin{array}{c}\text { Hydro inflow } \\
\text { scenario }\end{array}\end{array}$} & \multicolumn{2}{|c|}{ First period } & \multicolumn{3}{|c|}{ Second period } & \multicolumn{3}{|c|}{ Price change } \\
\hline & & & & \multirow{2}{*}{$\begin{array}{c}\text { Price (R\$/ } \\
\text { MWh) }\end{array}$} & \multirow{2}{*}{$\begin{array}{c}\text { Quantity } \\
\text { (MW-avg) }\end{array}$} & & \multirow{2}{*}{$\begin{array}{l}\text { Hydro Supply } \\
\text { (MW-avg) }\end{array}$} & \multirow{2}{*}{$\begin{array}{l}\text { Price (R\$/ } \\
\text { MWh) }\end{array}$} & \multirow{2}{*}{$\begin{array}{l}\text { Hydro Inflow } \\
\text { Scenario }\end{array}$} & \multirow{2}{*}{$\begin{array}{c}\text { Hydro Supply } \\
\text { (MW-avg) }\end{array}$} & \multirow{2}{*}{$\begin{array}{c}\text { Price (Present } \\
\text { value) (R\$/MWh) }\end{array}$} & \multirow{2}{*}{$\begin{array}{c}\text { First } \\
\text { Period }\end{array}$} & Seconc & \\
\hline & & & & & & & & & & & & & Scenario & Avg \\
\hline & & & & & & & & & low & 43,294 & 307.13 & & $50 \%$ & \\
\hline 1 & $\begin{array}{c}\text { Consolidated } \\
\text { (stationary state) }\end{array}$ & $6 \%$ & -0.3 & 205 & 65,000 & $\begin{array}{c}\text { Long term } \\
\text { average }\end{array}$ & 62,403 & 188.18 & medium & 50,234 & 270.94 & $-8 \%$ & $32 \%$ & $30 \%$ \\
\hline & & & & & & & & & high & 56,933 & 221.45 & & $8 \%$ & \\
\hline & & & & & & & & & low & 47,639 & 282.05 & & $38 \%$ & \\
\hline 2 & Consolidated & $6 \%$ & -0.3 & 205 & 65,000 & Long term & 62,403 & 188.18 & medium & 50,751 & 266.33 & $-8 \%$ & $30 \%$ & $23 \%$ \\
\hline & & & & & & & & & high & 58,670 & 205.55 & & $0 \%$ & \\
\hline & & & & & & & & & low & 57,351 & 218.59 & & $7 \%$ & \\
\hline 3 & Split up & $6 \%$ & -0.3 & 205 & 65,000 & $\begin{array}{l}\text { Long term } \\
\text { average }\end{array}$ & 63,376 & 175.04 & medium & 60,591 & 187.78 & $-15 \%$ & $-8 \%$ & $-10 \%$ \\
\hline & & & & & & & & & high & 65,341 & 146.50 & & $-29 \%$ & \\
\hline & & & & & & & & & low & 57,532 & 218.58 & & $7 \%$ & \\
\hline 4 & Split up & $3 \%$ & -0.3 & 205 & 65,000 & $\begin{array}{l}\text { Long term } \\
\text { average }\end{array}$ & 63,343 & 175.38 & medium & 62,371 & 174.47 & $-14 \%$ & $-15 \%$ & $-12 \% \%$ \\
\hline & & & & & & & & & high & 65,341 & 146.50 & & $-29 \%$ & \\
\hline & & & & & & & & & low & 47,452 & 380.51 & & $86 \%$ & \\
\hline 5 & Split up & $6 \%$ & -0.1 & 205 & 65,000 & $\begin{array}{c}\text { Long term } \\
\text { average }\end{array}$ & 61,827 & 165.05 & medium & 58,776 & 221.46 & $-19 \%$ & $8 \%$ & $33 \%$ \\
\hline & & & & & & & & & high & 59,096 & 218.61 & & $7 \%$ & \\
\hline & & & & & & & & & low & 59,530 & 195.83 & & $-4 \%$ & \\
\hline $6^{*}$ & Split up & $6 \%$ & -0.5 & 205 & 65,000 & $\begin{array}{l}\text { Long term } \\
\text { average }\end{array}$ & 66,515 & 167.44 & medium & 64,947 & 166.49 & $-18 \%$ & $19 \%$ & $-20 \%$ \\
\hline & & & & & & & & & high & 72,298 & 126.74 & & $-38 \%$ & \\
\hline & & & & & & & & & low & 56,832 & 195.83 & & $9 \%$ & \\
\hline 7 & Split up & $6 \%$ & -0.3 & 150 & 65,000 & Long term & 63,143 & 129.15 & medium & 62,407 & 126.74 & $-14 \%$ & $-16 \%$ & $-11 \%$ \\
\hline & & & & & & & & & high & 64,703 & 110.70 & & $-26 \%$ & \\
\hline & & & & & & & & & low & 55,300 & 111.67 & & $12 \%$ & \\
\hline 8 & Split up & $6 \%$ & -0.3 & 100 & 65,000 & $\begin{array}{c}\text { Long term } \\
\text { average }\end{array}$ & 63,1819 & 87.43 & medium & 60,309 & 93.14 & $-13 \%$ & $-7 \%$ & $-8 \%$ \\
\hline & & & & & & & & & high & 65,865 & 72.32 & & $-28 \%$ & \\
\hline & & & & & & & & & low & 56,355 & 209.17 & & $2 \%$ & \\
\hline 9 & Split up & $6 \%$ & -0.3 & 205 & 63,000 & $\begin{array}{c}\text { Long term } \\
\text { average }\end{array}$ & 62,764 & 159.40 & medium & 60,261 & 175.02 & $-22 \%$ & $-15 \%$ & $-14 \%$ \\
\hline & & & & & & & & & high & 63,457 & 143.85 & & $-30 \%$ & \\
\hline & & & & & & & & & low & 59,268 & 218.61 & & $7 \%$ & \\
\hline 10 & Split up & $6 \%$ & -0.3 & 205 & 67,000 & Long term & 64,357 & 186.33 & medium & 63,186 & 183.88 & $-9 \%$ & $-10 \%$ & $-8 \%$ \\
\hline & & & & & & & & & high & 65,647 & 162.78 & & $-21 \%$ & \\
\hline & & & & & & & & & low & 57,392 & 218.18 & & $6 \%$ & \\
\hline 11 & Split up & $6 \%$ & -0.3 & 205 & 65,000 & El ninõ & 70,129 & 115.90 & medium & 61,389 & 181.60 & $-43 \%$ & $-11 \%$ & $-11 \%$ \\
\hline & & & & & & & & & high & 65,440 & 145.52 & & $-29 \%$ & \\
\hline & & & & & & & & & low & 53,501 & 244.58 & & $19 \%$ & \\
\hline 12 & Split up & $6 \%$ & -0.3 & 205 & 65,000 & La ninã & 61,157 & 195.63 & medium & 59,825 & 195.00 & $-5 \%$ & $-5 \%$ & $-4 \%$ \\
\hline & & & & & & & & & high & 64,582 & 152.96 & & $-25 \%$ & \\
\hline & & & & & & & & & low & 52,668 & 252.80 & & $23 \%$ & \\
\hline 13 & Split up & $6 \%$ & -0.3 & 205 & 65,000 & 5 worst inflows & 54,383 & 253.10 & medium & 57,460 & 217.52 & $23 \%$ & $6 \%$ & $4 \%$ \\
\hline & & & & & & & & & high & 63,005 & 168.21 & & $-18 \%$ & \\
\hline & & & & & & & & & low & 57,351 & 218.59 & & $7 \%$ & \\
\hline 14 & Split up & $6 \%$ & -0.3 & 205 & 65,000 & 5 best inflows & 89,829 & 0.00 & medium & 62,043 & 176.89 & $-100 \%$ & $-14 \%$ & $-11 \%$ \\
\hline & & & & & & & & & high & 64,790 & 150.90 & & $-26 \%$ & \\
\hline
\end{tabular}

Source: Authors' elaboration. 
In the following cases (3-14) we consider a different market structure, in which Eletrobras' four subsidiaries - Furnas, Chesf, Eletronorte and Eletrosul - are split up to operate independently from one another and the holding company, Eletrobras. This is an obvious first move that would significantly reduce concentration.

Case 3 is the base case considering the split up of Eletrobras' subsidiaries. The simulation indicates that the split would provide sufficient competitive pressure to discipline prices. The equilibrium prices in this simulation are all below the 'reference equilibrium' price:

- $\mathrm{R} \$ 175.04 / \mathrm{MWh}(-14 \%)$ in the first period,

- $\mathrm{R} \$ 174.47 / \mathrm{MWh}(-15 \%)$ in the second-period 'medium hydro' scenario, and

- $\mathrm{R} \$ 146.50 / \mathrm{MWh}$ (-29\%) in the second-period 'high hydro' scenario;

except in the 'low hydro' scenario for the second period, in which it is higher: $\mathrm{R} \$$ $218.58 / \mathrm{MWh}(+7 \%)$ above the 'reference equilibrium price'. The concern in this case may be "too much" competition.

The concern that arises from this simulation is that, given the current market structure, average market equilibrium prices may be insufficient to recover investments. Prices are not too far off from the 'reference equilibrium', however, to represent a major threat to market sustainability.

The ideal situation would be to have prices range above and below the 'reference equilibrium' depending on hydro inflow conditions to incent both consumers and producers to sign long-term contracts protecting themselves from high prices and low prices, respectively.

Cases 4 through 10 are used for sensibility analysis purposes.

Case 4 evaluates the market equilibrium if the discount rate were reduced from $6 \%$ to $3 \%$. As expected, the lower discount rate leads to slightly higher prices in the first period and lower prices in the second period, as producers store more water in the hydro reservoirs to meet future demand.

Case 5 gauges the effect of a steeper demand curve. When the price-elasticity of demand (at the 'reference equilibrium') is reduced from -0.3 to -0.1 , prices rise considerably, particularly as hydro inflow conditions deteriorate. In the second-period, 'low hydro' scenario, the equilibrium price rises to R\$380.51/MWh (+86\%).

Case 6 examines the case of a flatter linear demand function, constructed by considering the slope derived from a price-elasticity of -0.5 at the 'reference equilibrium' The model did not converge in 250 iterations allowed in the program. With higher elasticities, the 'sales effect' becomes more prominent, making the simulation convergence process less efficient. The prevailing prices in the iterations were in the $\mathrm{R} \$ 160-180 /$ MWh range, which is consistent with expectations, given the flatter demand curve. 
Cases 7 and 8 evaluate the effect of the 'reference equilibrium' price utilized in the simulations. The reference price of $\mathrm{R} \$ 205 / \mathrm{MWh}$ is the current average price of longterm contracts in Brazil. In order to gain some insight on how this parameter affects the simulations, we adopted two different 'reference equilibrium' prices of R \$150/MWh and $\mathrm{R} \$ 100 / \mathrm{MWh}$. The effect of the lower reference price is a dislocation of the hydro demand curve to the right, which results in a more intensive dispatch of hydropower plants (lower thermo power dispatch) and, consequently, lower equilibrium prices in 'medium' and 'high' inflow scenarios. However, when 'low' inflow conditions occur, second-period prices tend to be higher because of the lower system reservoir levels due to the more intense hydropower dispatch in the first period.

Cases 9 and 10 examine the effect of the 'reference equilibrium' quantity of energy demanded. Case 9 considers a lower demand of $63 \mathrm{GW}$-avg (compared to $65 \mathrm{GW}$-avg in the base case), while Case 10 considers a demand of $67 \mathrm{GW}$-avg. As expected, a lower demand results in lower equilibrium prices in all periods and scenarios, and a higher demand results in higher equilibrium prices.

Cases 11 through 14 enable one to assess how hydro inflow conditions impact equilibrium.

Case 11 shows the equilibrium prices drop when hydro inflow conditions are equivalent to those observed in El Niño conditions, which, in Brazil, results in increased rainfall and, consequently, higher hydro inflows.

Case 12 shows that, when the La Niña climatic phenomena occurs, hydro inflows are reduced, resulting in higher prices.

Case 13 and 14 show the equilibrium obtained given the five worst and five best inflow scenarios extracted from the historical record. The results are consistent with expectations. Case 14 shows an interesting situation in which the first period price drops to zero, because there is no more storage capacity available to store water from the first period to be used in the second one. Overall, the simulations suggest that the price variations are mostly impacted by the aggregate hydro inflows, and not so much by how the hydro inflows are distributed between market players.

Cases 15 through 24 are a repetition of the exercises done in Cases 2-6 and 9-14 considering a constant-elasticity demand rather than the linear demand. The results are similar to those obtained in the linear demand case. The main difference is that the constant-elasticity of demand results in larger price variations in a situation that deviates more from the reference equilibrium. As observed with the linear demand (Case 6), when the price elasticity of demand was raised to -.5 (Case 18), convergence was not achieved in the stipulated number of iterations allowed by the program, although prices roamed at a lower level than the reference equilibrium, as expected. 
Table 2 - Simulation results considering a constant-elasticity demand

\begin{tabular}{|c|c|c|c|c|c|c|c|c|c|c|c|c|c|c|}
\hline \multicolumn{7}{|c|}{ CASE SPECIFICATION } & \multicolumn{8}{|c|}{ RESULTS } \\
\hline \multirow{3}{*}{ Case } & \multirow{3}{*}{ Eletrobras } & \multirow{3}{*}{ Discount rate } & \multirow{3}{*}{ Price elasticity } & \multicolumn{2}{|c|}{ Reference equilibruim } & \multirow{3}{*}{$\begin{array}{c}\text { First period } \\
\begin{array}{c}\text { Hydro inflow } \\
\text { scenario }\end{array}\end{array}$} & \multicolumn{2}{|c|}{ First period } & \multicolumn{3}{|c|}{ Second period } & \multicolumn{3}{|c|}{ Price change } \\
\hline & & & & \multirow{2}{*}{ Price $(\mathrm{R} \$ / \mathrm{MWh})$} & \multirow{2}{*}{$\begin{array}{c}\text { Quantity } \\
\text { (MW-avg) }\end{array}$} & & \multirow{2}{*}{$\begin{array}{l}\text { Hydro Supply } \\
\text { (MW-avg }\end{array}$} & \multirow{2}{*}{ Price (R\$/MWh) } & \multirow{2}{*}{$\begin{array}{l}\text { Hydro Inflow } \\
\text { Scenario }\end{array}$} & \multirow{2}{*}{$\begin{array}{l}\text { Hydro Supply } \\
\text { (MW-avg) }\end{array}$} & \multirow{2}{*}{$\begin{array}{l}\text { Price (Present value) } \\
\text { (R\$/MWh) }\end{array}$} & \multirow{2}{*}{$\begin{array}{c}\text { First } \\
\text { Period }\end{array}$} & \multicolumn{2}{|c|}{ Second period } \\
\hline & & & & & & & & & & & & & Scenario & Avg \\
\hline \multirow{3}{*}{15} & \multirow{3}{*}{ Split up } & \multirow{3}{*}{$6 \%$} & \multirow{3}{*}{-0.3} & \multirow{3}{*}{205} & & & & & low & 53,036 & 259.42 & & $27 \%$ & \\
\hline & & & & & 65,000 & $\begin{array}{l}\text { Long term } \\
\text { average }\end{array}$ & 63,541 & 176.24 & medium & 62,134 & 176.89 & $-14 \%$ & $-14 \%$ & $-12 \%$ \\
\hline & & & & & & & & & high & 75,353 & 103.46 & & $-50 \%$ & \\
\hline & & & & & & & & & low & 51,829 & 271.02 & & $32 \%$ & \\
\hline 16 & Split up & $3 \%$ & -0.3 & 205 & 65,000 & $\begin{array}{l}\text { Long term } \\
\text { average }\end{array}$ & 66,237 & 155.85 & medium & 58,473 & 208.28 & $-24 \%$ & $2 \%$ & $-3 \%$ \\
\hline & & & & & & & & & high & 71,221 & 119.35 & & $-42 \%$ & \\
\hline & & & & & & & & & low & 34,509 & 2187.09 & & $967 \%$ & \\
\hline 17 & Split up & $6 \%$ & -0.1 & 205 & 65,000 & $\begin{array}{c}\text { Long term } \\
\text { average }\end{array}$ & 61,885 & 167.53 & medium & 48,389 & 457.03 & $-18 \%$ & $132 \%$ & $394 \%$ \\
\hline & & & & & & & & & high & 49,268 & 396.13 & & $93 \%$ & \\
\hline & & & & & & & & & low & 57,423 & 208.74 & & $2 \%$ & \\
\hline $18^{*}$ & Split up & $6 \%$ & -0.5 & 205 & 65,000 & $\begin{array}{l}\text { Long term } \\
\text { average }\end{array}$ & 68,629 & 162.22 & medium & 67,700 & 156.44 & $-21 \%$ & $-24 \%$ & $-12 \%$ \\
\hline & & & & & & & & & high & 80,031 & 115.91 & & $-43 \%$ & \\
\hline & & & & & & & & & low & 53,457 & 233.41 & & $14 \%$ & \\
\hline 19 & Split up & $6 \%$ & -0.3 & 205 & 63,000 & $\begin{array}{c}\text { Long term } \\
\text { average }\end{array}$ & 64,133 & 155.34 & medium & 61,884 & 162.07 & $-24 \%$ & $-21 \%$ & $-22 \%$ \\
\hline & & & & & & & & & high & 74,602 & 97.77 & & $-52 \%$ & \\
\hline & & & & & & & & & low & 52,208 & 233.41 & & $34 \%$ & \\
\hline 20 & Split up & $6 \%$ & -0.5 & 205 & 67,000 & $\begin{array}{l}\text { Long term } \\
\text { average }\end{array}$ & 64,473 & 186.33 & medium & 56,174 & 243.95 & $-9 \%$ & $19 \%$ & $4 \%$ \\
\hline & & & & & & & & & high & 73,328 & 120.40 & & $-41 \%$ & \\
\hline & & & & & & & & & low & 54,597 & 242.89 & & $18 \%$ & \\
\hline 21 & Split up & $6 \%$ & -0.3 & 205 & 65,000 & El Ninõ & 71,025 & 128.08 & medium & 62,182 & 176.48 & $-38 \%$ & $-14 \%$ & $-15 \%$ \\
\hline & & & & & & & & & high & 75,353 & 103.46 & & $-50 \%$ & \\
\hline & & & & & & & & & low & 51,844 & 270.80 & & $32 \%$ & \\
\hline 22 & Split up & $6 \%$ & -0.3 & 205 & 65,000 & La Ninã & 61,184 & 195.63 & medium & 56,138 & 223.64 & $-5 \%$ & $9 \%$ & $3 \%$ \\
\hline & & & & & & & & & high & 67,336 & 139.15 & & $-32 \%$ & \\
\hline & & & & & & & & & low & 48,115 & 289.43 & & $41 \%$ & \\
\hline 23 & Split up & $6 \%$ & -0.3 & 205 & 65,000 & $\begin{array}{l}5 \text { worst } \\
\text { inflows }\end{array}$ & 54,595 & 258.42 & medium & 57,162 & 221.46 & $26 \%$ & $8 \%$ & $7 \%$ \\
\hline & & & & & & & & & high & 66,237 & 146.50 & & $-29 \%$ & \\
\hline & & & & & & & & & low & 55,485 & 231.64 & & $13 \%$ & \\
\hline 24 & Split up & $6 \%$ & -0.3 & 205 & 67,000 & 5 best inflows & 90,006 & 69.45 & medium & 65,580 & 150.38 & $-66 \%$ & $-27 \%$ & $-20 \%$ \\
\hline & & & & & & & & & high & 72,655 & 112.43 & & $-45 \%$ & \\
\hline
\end{tabular}

Source: Authors' elaboration. 


\subsection{DISCUSSION}

The results suggest that bid-based pricing and operation is feasible in the Brazilian electricity market. The projected equilibrium prices would tend to increase significantly given the current market structure, but, if the four subsidiaries of Eletrobras were split up to operate as independent private firms (i.e. maximizing their own individual profits), market competition would provide sufficient pressure to discipline prices in average hydro inflow scenarios.

In periods of droughts, prices are expected to rise, but this is a transitory condition from which market players can protect themselves by adopting long-term contracts. In normal hydro inflow conditions, the projected equilibrium prices with the Eletrobras divestiture are not too far off from current prices.

The sensitivity analysis considering variations in the main parameters utilized in the simulation model shows that the results are robust. The only exception is the priceelasticity of demand. Most simulations considered the linear demand with a priceelasticity of -0.3 at the 'reference equilibrium' point. However, if demand price elasticity were lower, the current market structure (even with the Eletrobras divestiture) would not be sufficient to discipline prices. Nevertheless, the supposition of a price of elasticity of -0.3 at current prices seems to be rather conservative, given various econometric estimates and the expectation that price-elasticity of demand should increase in the coming years as new technologies are adopted.

As in any analysis of this sort, it is important to be mindful of the limitations of the adopted model. The assumption of demand functional form is an important assumption. Another important feature is the aggregation procedure described in section 4.3.1. In the aggregation process, the direct linkages between individual hydropower plants are lost, which may give rise to distortions. While the aggregate values are correct, the exact values of individual players may be different, which could result in a slightly different competitive dynamic.

These results provide reassurance that bid-based pricing and dispatch is viable. Nevertheless, it would be desirable to reduce market concentration, to discourage shared ownership of power plants and to consolidate ownership of run-of-river hydropower plants directly downstream from the controllable hydropower plants.

\section{CONCLUSIONS}

Simulation models, such as the Cournot-Nash model presented in this paper, are useful instruments to help guide policymakers in market reforms. Many industries, 
such as the electric power industry, can adopt regulatory reforms to establish competitive markets for particular bundles of goods and services.

Quite often policymakers are reluctant to engage in such reforms because of the uncertainty regarding their effects. Scrupulous market simulation can be a potent tool in this process, by reducing uncertainty with regard to the expected results of market reforms, by providing a better understanding of the effects of different policy decisions, and by bringing insights on market dynamics in different situations.

Likewise, for antitrust authorities, market simulation is a potent tool to evaluate structural changes in the market, either due to horizontal mergers or to ordered divestitures.

\section{REFERENCES}

ABREU, M.; SANT'ANNA, A. Relatórios de Pesquisa em Engenharia de Produção, v. 9, n. 5, p. $1-14,2009$.

ANEEL - AGÊNCIA NACIONAL DE ENERGIA ELÉTRICA. BIG - Banco de Informações de Geração. ANEEL. Aug. 2016a. Available at: <http://www.aneel.gov.br/informacoes-tecnicas>.

ANEEL - AGÊNCIA NACIONAL DE ENERGIA ELÉTRICA. Cadeia societária de empresas de geração de energia elétrica. ANEEL. Aug. 2016b. Available at: <http://www.aneel.gov.br/ pae>.

ANDRADE, T.; LOBÃO, W. Elasticidade renda e preço da demanda residencial de energia elétrica no Brasil. Texto de Discussão, IPEA, n. 489, 1997.

ASSUNÇÃO, J.; REZENDE, L.; SCHUTZE, A. Elasticidade preço da demanda residencial de energia elétrica no Brasil. Rio de Janeiro: PUC-Rio, 2015.

BANZHAF, J. Weighted voting doesn’t work: a mathematical analysis. Rutgers Law Review, v. 19, n. 2, p. 317-343, 1965.

BORENSTEIN, S.; BUSHNELL, J. An empirical analysis of the potential for market power in California’s electricity industry. Journal of Industrial Economics, v. 47, n. 3, p. 282-323, 1999.

BORENSTEIN, S.; BUSHNELL, J.; KNITTEL, C. Market power in electricity markets: beyond concentration measures. Energy Journal, v. 20, n. 4, p. 65-88, 1999.

CADE - CONSELHO ADMINISTRATIVO DE DEFESA ECONÔMICA. Guia de Análise de Atos de Concentração Horizontal. Brasilia: CADE, 2016. Available at: <http://www.cade.gov. br/acesso-a-informacao/publicacoes-institucionais/guias_do_Cade/guia-para-analise-deatos-de-concentracao-horizontal.pdf $>$.

DE VRIES, A. The Banzhaf Index of Power. Math IT, University of Applied Science, 2016. Available at: <http://math-it.org/Mathematik/MathPol/Banzhaf.html $>$.

FARRELL, J.; SHAPIRO, C. Horizontal mergers: an equilibrium analysis. The Amercian Economic Review, v. 80, n. 1, p. 107-126, 1990. 
GARCIA, C.; FARINA, E. Concorrência e as participações minoritárias entre firmas rivais. Economia Aplicada,v. 17, n. 1, p. 71-89, 2013.

INPE - INSTITUTO NACIONAL DE PESQUISAS ESPACIAIS. Monitoramento do El Niño. Cachoeira Paulista: CPTEC, 2017. Available at: <http://enos.cptec.inpe.br/>.

KREPS, D.; SCHEINKMAN, J. Quantity precommitment and Bertrand competition yields Cournot outcomes. Rand Journal of Economics, v. 14, n. 2, p. 326-337, 1983.

LAZZARINI, S. Capitalismo de laços: os donos do Brasil e suasconexões. Rio de Janeiro: Elsevier, 2011.

MODIANO, E. Elasticidade renda e preços da demanda da energia elétrica no Brasil. Texto para Discussão, Departamento de Economia, PUC-Rio, n. 68, 1984.

ONS - OPERADOR NACIONAL DO SISTEMA. Diagrama esquemático das usinas hidrelétricas do SIN. ONS, 2017a. Available at: <http://ons.org.br/paginas/sobre-o-sin/mapas>.

ONS - OPERADOR NACIONAL DO SISTEMA. Programa mensal da operação (PMO). ONS, Jan. 2017b.

SALOP, S.; O'BRIEN, D. Competitive effects of partial ownership: financial interest and corporate control. Antitrust Law Journal, v. 67, p. 559-614, 2000.

SCHMIDT, C.; LIMA, M. A demanda por energia elétrica no Brasil. Revista Brasileira de Economia, v. 58, n. 1, p. 67-98, 2004.

U.S. DEPARTMENT OF JUSTICE. Horizontal Merger Guidelines. Washington, DC: US Department of Justice; Federal Trade Commission, Aug. 2010. Available at: <https://www.justice.gov/atr/ horizontal-merger-guidelines-08192010>.

WILLIG, R. Merger analysis, industrial organization theory, and merger guidelines. Brookings Papers: Microeconomics, p. 281-332, 1991. 